\title{
ESTUDO DO IMPACTO DE UM CURSO MBA EM CONTROLADORIA NA EVOLUÇÃO DE SEUS EGRESSOS
}

\author{
Fábio Frezatti \\ Professor Associado do Depto. de Contabilidade e Atuária da FEA-USP \\ E-mail: frezatti@usp.br \\ Sílvia Kassai \\ Professora Doutora do Depto. de Contabilidade e Atuária da FEA-USP \\ E-mail: sikassai@usp.br
}

\section{RESUMO}

O ensino de pós-graduação tem evoluído de maneira muito acentuada a partir da premissa que traz conseqüências práticas em termos de benefícios aos participantes e às empresas. A grande busca tem se concentrado nos Master of Business Administration, criação norte-americana do início do século passado, que se expandiu para praticamente todas as partes do mundo. $O$ estudo dos impactos dos cursos tem sido feito nos ambientes profissional e acadêmico. Abordando a evolução dos salários pré e pós MBA, 0 alcance de novos níveis na carreira e até mesmo a postura e aquisição de competências, os estudos buscam detectar os fatores que determinam o sucesso dos egressos dos cursos. A presente pesquisa examina a população de um programa brasileiro que foi implantado em 1994 e conta hoje com 17 turmas já formadas. Através de um questionário foram examinados o impacto do curso conforme percebido pelos egressos e sua evolução na carreira pós-MBA. Essas informações foram cruzadas com o perfil dos alunos e com seu desempenho acadêmico, buscando determinar os fatores que implicam no sucesso dos alunos após o curso. Para tanto, a pesquisa valeu-se da estatística descritiva e da Análise por Tabela de Contingência. Ao final, são apresentadas algumas conclusões iniciais e questões para aprofundamento.

Palavras-chave: MBA, Ensino em Controladoria, Análise de egressos.

\section{ABSTRACT}

Post-graduate education has evolved in a very accentuated way on the basis of the premise that brings about practical consequences in terms of benefits to participants and companies. Demand has paramountly been concentrated in Master of Business Administration programs, a NorthAmerican creation from the beginning of the last century that has practically expanded all over the world. The impact of these courses has been studied in the professional and academic spheres. Dealing with salary evolution before and after the MBA, the achievement of new career levels and even the acquisition and attitude towards competencies, studies try to detect the factors that determine the success of MBA-graduates. This research examines the population of a Brazilian program implanted in 1994, in which 17 classes have already graduated. By means of a questionnaire, we examined the course impact as perceived by the graduates and their post-MBA career evolution. This information was crossed with student profile and academic performance, in order to determine the factors that affect the students' success after the course. For this purpose, the research used descriptive statistics and Contingency Table Analysis. Finally, we present some preliminary conclusions and questions for further research.

Keywords: MBA, Controllership Learning, Graduate student analysis. 


\section{CENÁRIO}

O final do século XX marcou uma série de mudanças dentro do mundo empresarial. A qualificação profissional e a reciclagem constante passaram a ser determinantes da empregabilidade. A flexibilização das formas de trabalho, a terceirização e o crescimento das atividades de consultoria marcaram profundamente o contrato tradicional capital $x$ mão-de-obra, trazendo a responsabilização crescente do profissional individualmente pela busca de oportunidades de formação e aperfeiçoamento. A qualificação universitária obrigatória foi substituída pela exigência de pósgraduação e as empresas passaram a cobrar dos executivos a efetividade dos conhecimentos adquiridos e sua aplicabilidade em situações empresariais que se alteram constantemente. Os cursos de pósgraduação assumiram um papel preponderante nesse quadro. Representados pelos cursos de especialização, MBA, Mestrado e Doutorado ganharam um ritmo crescente de procura e tiveram seu impacto analisado e discutido. O presente estudo busca examinar o impacto dos cursos de MBA na evolução profissional de seus egressos, através de um estudo exploratório aplicado a um programa que teve seu início em 1994 e que, hoje, conta com 17 turmas já concluídas. Através de um questionário, foram examinados o impacto do curso conforme percebido pelos egressos e a evolução de sua carreira pós-MBA. Essas informações foram cruzadas com o perfil do aluno e seu desempenho acadêmico durante o curso. Para tanto, foram utilizadas a Estatística Descritiva e a Análise por Tabela de Contingência. Ao final, são apresentadas algumas conclusões e diversas questões para aprofundamento.

\section{O PAPEL DO PROGRAMA MBA NA ÁREA EDUCACIONAL}

O crescimento do oferecimento dos cursos MBA é um fenômeno em todo o mundo. Nos Estados Unidos, onde foram introduzidos em 1908, os dados mostram um aumento de $27 \%$ no oferecimento de programas executivos entre 1987 e 1991. A Inglaterra seguiu a tendência apenas na segunda metade do século, com a introdução de programas da London Business School e da Manchester Business School, apesar de, em alguns países da Europa, o MBA ainda não ter se estabelecido como uma qualificação reconhecida (Baruch e Peiperl, 2000:70). Os programas MBA apresentam-se em duas modalidades principais: programas part-time que buscam conciliar as atividades profissionais ao estudo, tendo como público executivos com o mínimo de 5 anos de experiência, chamados de Executive MBAs, e os tradicionais programas MBA que são full-time e se destinam a recém-formados que buscam um rápido impulso em suas carreiras.

No Brasil, os primeiros programas foram introduzidos no final da década de 80 e início dos anos 90 . Rapidamente, evoluíram com o oferecimento de cursos generalistas (Executive MBA) e especialistas, em tempo parcial ou integral.

Diversos estudos apontam as razões que, mais freqüentemente, justificam a opção de cursar um MBA: ampliar as oportunidades de trabalho, desejo de alterar o perfil profissional, obter conhecimentos gerais de negócios, estímulo à experiência intelectual, aumentar os ganhos ou a autoconfiança (Ascher, 1984 Apud Baruch e Peiperl, 2000:69; Luker, Browers e Powers, 1989 Apud Baruch e Peiperl, 2000:69).

Para avaliar os programas e auxiliar no processo de escolha existem rankings tradicionais entre os quais os preparados e divulgados pela revista Business Week, pelo jornal Wall Street Journal e o relatório U.S. News e World Report. Algumas dessas publicações incluem a análise de programas europeus, latino-americanos e asiáticos. Os rankings também foram adotados recentemente no Brasil entre os quais: Guia America Economia de MBAs, Guia Você S. A. - Os Melhores MBAs do Brasil e Guia Pós-Graduação e $M B A$ - Folha Empregos. Apesar de fornecerem muitas informações a respeito dos programas, os rankings têm sua abrangência e impacto discutidos por acadêmicos e profissionais (Wuorio, 2001:26).

Estudos acadêmicos buscam determinar o impacto do curso na carreira dos egressos. (Baruch e Peiperl, 2000:74) compararam grupos de executivos que haviam cursado MBA com outros que não o haviam feito em 4 empresas inglesas. Através de questionários, pesquisaram 186 executivos, dos quais 57 haviam cursado MBA (30\%). Entre os pesquisados $77 \%$ eram homens, o que reflete a participação em MBA em geral, e a idade média era de 35,2 anos. As conclusões são que, em todos os elementos pesquisados relacionados 
à competência, foram percebidos níveis mais altos entre os egressos de MBA. Assim, o estudo confirma a noção de que o MBA, realmente, contribui para a formação de competências. Não foram identificadas diferenças salariais ou na evolução da carreira. Os egressos de MBAs demonstraram maiores níveis de autoconfiança. Apesar de bastante referida, não foi constatada entre os grupos diferença estatística significante na disposição para deixar a empresa.

Forrester (1986 Apud Baruch e Peiperl, 2000:69), em um estudo com 1.127 formados no MBA da London Business School, encontrou um aumento substancial nos salários pós-MBA, entre 24 e 54\% dos salários pré-MBA.

Levantamentos da UK Association of MBAs (Schofield, 1996:40), sobretudo em programas de tempo parcial, concluíram que, em 18 meses, 50\% dos egressos haviam sido promovidos e, dentre estes, $50 \%$ haviam evoluído mais de um nível na carreira.

Pesquisa efetuada no Brasil pela Datafolha entrevistou 264 executivos que já haviam cursado ou estavam cursando pós-graduação. Desse universo, $74 \%$ tiveram mudanças na vida profissional, 50\% conseguiram aumento de salário e $44 \%$ foram promovidos. A pós-graduação incluiu, na pesquisa, cursos de mestrado (34\%), doutorado (13\%) e especialização (52\%). Dados da Coordenação para o Aperfeiçoamento do Pessoal de Nível Superior (CAPES) indicam, ainda, um aumento de $229 \%$ do número de estudantes com título de mestrado e de $279 \%$ no total de doutores formados, entre 1999 e 2000 (FoIha de São Paulo, 2002). Os dados não existem para os cursos de MBA, mas o aumento do oferecimento de programas pode ser constatado pela consulta aos rankings já mencionados.

Mintzberg e Lampel (2001:244), no entanto, criticam os tão propalados efeitos do MBA, mencionando que, dentre os mais bem sucedidos executivos americanos, freqüentemente, estão incluídos nomes como Bob Galvin da Motorola, Bill Gates da Microsoft, Andy Grove da Intel e Jack Welch da General Motors. Os dois primeiros nunca concluíram seus estudos universitários; os dois últimos obtiveram o Ph.D. em engenharia química. Por outro lado, pode ser citado o artigo da Fortune (1999), Por que os CEOs falham: das 33 empresas listadas no artigo, $40 \%$ dos CEOs tinham MBA.
As críticas ecoaram no Brasil em artigo de Wood Jr. (2001:41) que pontua que “(...) aqui, o conceito de $M B A$, criticado na versão original, foi mal-entendido e digerido, misturado com resquícios de um ensino esclerosado de terceiro grau, temperado com doses generosas de faz-de-conta e reciclado para uma massa consumidora sem paladar ou bom senso, mas dotada de um senso de urgência cego. (...) Talvez seja mais realista interpretar o fenômeno como um contrato psicológico coletivo delirante: os professores fingem que ensinam, os alunos fingem que aprendeme as empresas fingem que valorizam o capital humano e que ficam mais competitivas".

Assim, o tema de pesquisa sobre o impacto dos cursos MBAs está longe de se esgotar. Ao contrário, carece de abordagens estruturadas que permitam o seu entendimento. Em decorrência do acima exposto, a questão de pesquisa deste trabalho é a seguinte: quais fatores podem ter relacionamento com o sucesso profissional do aluno que cursa um programa $M B A$ ?

\section{PROJETO E DESENVOLVIMENTO DA PESQUISA}

O programa MBA em estudo foi implantado em 1994 e conta atualmente com 17 turmas já concluídas. Com o total de 1.000 horas, distribuídas por 26 disciplinas, destina-se a profissionais das áreas de Controladoria, Contabilidade e Finanças. Os alunos têm em cada disciplina avaliações individuais, na forma definida pelos professores responsáveis, às quais são atribuídas conceitos de "A" a "C". Para concluir o curso, devem obter conceito mínimo geral "B" e 85\% de freqüência.

Desde de sua fundação, formou 299 executivos, sendo $84 \%$ homens e $16 \%$ mulheres, provenientes preponderantemente de cursos de graduação em Administração, Contabilidade e Economia, que totalizam $68 \%$ dos ingressantes. Outras graduações envolvem as áreas de Engenharia, Análise de Sistemas, Direito, Ciências Sociais e Publicidade. Ao ingressarem no curso, 98 alunos já haviam cursado um pós-graduação.

A média de tempo decorrido, desde a graduação, é de 11 anos, com desvio-padrão de 6 anos, e apenas $11 \%$ dos egressos tinha, quando iniciou o curso, menos de 3 anos de graduado. A idade média, 
quando do ingresso no curso, é de 35,8 anos, com desvio-padrão de 6 anos. $O$ curso teve turmas nas cidades de São Paulo, Campinas e Curitiba.

Muito embora o programa tenha tido mais de 360 alunos inscritos, dada a sua pretensão em se constituir em um programa diferenciado e de alta qualidade, a avaliação e a freqüência são consideradas como pontos críticos de atenção. Assim, a população para a pesquisa foi constituída pelos alunos que encerraram o programa desde a primeira turma, totalizando 299 pessoas. Os egressos foram contatados por $e$ mail e por telefone, sendo assegurada a proporcionalidade em função da turma, idade e sexo, em relação à composição do universo de formados no MBA. Responderam ao questionário 160 alunos que puderam ser incorporados ao trabalho, representando $55,9 \%$ do total, um nível de respostas significativo para esse tipo de pesquisa, independentemente do seu significado perante o erro estatístico. Nesse sentido, os alunos que não concluíram o curso, por ainda estarem participando do programa ou terem sido desligados, não fazem parte da população-alvo.
Os programas fechados também foram eliminados do universo analisado no sentido de evitar viés cuja conseqüência exigiria análises não previstas neste trabalho. As informações para população e amostra são apresentadas na Tabela 1.

A tabela trata tanto da população como da amostra, esta última projetada a partir da aceitação de um erro amostral de $15 \%$. Os tamanhos das turmas são relativamente diferentes, permitindo-se conjecturar sobre os efeitos que possam causar na pesquisa.

A baixa participação feminina faz com que a variável sexo não tenha seus efeitos investigados.

A idade considerada, nessa tabela, é a que os participantes têm atualmente e não a com que iniciaram o programa. O motivo dessa abordagem é o fato de que o nível de empregabilidade do pesquisado é o atual, depois de decorrido certo tempo do término do curso. Em alguns casos, pela peculiaridade da idade ser considerada relativamente avançada para o mercado, existe impacto no resultado da pesquisa, sendo encontrados casos de aposentadoria e mesmo de desemprego.

Tabela 1 - Definição da amostra para erro de $15 \%$, levando em conta sexo e idade

\begin{tabular}{|c|c|c|c|c|c|c|c|c|c|c|}
\hline \multirow[b]{2}{*}{ Turma } & \multirow[b]{2}{*}{ Local } & \multicolumn{3}{|c|}{ Total } & \multicolumn{3}{|c|}{ Amostra } & \multicolumn{3}{|c|}{ Idade (em anos) } \\
\hline & & Masc. & Fem. & Total & Masc. & Fem. & Total & Masc. & Fem. & Total \\
\hline 1 & São Paulo & 17 & 2 & 19 & 12 & 1 & 13 & 40 & 45 & 41 \\
\hline 2 & São Paulo & 13 & 2 & 15 & 10 & 1 & 11 & 45 & 37 & 44 \\
\hline 3 & São Paulo & 17 & 1 & 18 & 12 & 1 & 13 & 42 & 31 & 41 \\
\hline 4 & São Paulo & 13 & 2 & 15 & 10 & 1 & 11 & 38 & 38 & 38 \\
\hline 5 & São Paulo & 22 & 2 & 24 & 14 & 2 & 16 & 40 & 36 & 40 \\
\hline 6 & São Paulo & 13 & 3 & 16 & 10 & 2 & 12 & 39 & 40 & 40 \\
\hline 7 & São Paulo & 17 & 6 & 23 & 11 & 4 & 15 & 55 & 37 & 51 \\
\hline 8 & São Paulo & 14 & 4 & 18 & 10 & 3 & 13 & 37 & 35 & 37 \\
\hline 9 & São Paulo & 18 & 8 & 26 & 11 & 5 & 16 & 38 & 33 & 37 \\
\hline 10 & São Paulo & 18 & 2 & 20 & 12 & 2 & 14 & 39 & 34 & 39 \\
\hline 11 & São Paulo & 12 & 4 & 16 & 9 & 3 & 12 & 35 & 37 & 36 \\
\hline 12 & São Paulo & 11 & 2 & 13 & 9 & 1 & 10 & 35 & 38 & 36 \\
\hline 13 & Curitiba & 20 & 2 & 22 & 11 & 2 & 13 & 43 & 43 & 43 \\
\hline 14 & Curitiba & 11 & 2 & 13 & 9 & 1 & 10 & 40 & 38 & 39 \\
\hline 15 & Curitiba & 21 & 2 & 23 & 14 & 1 & 15 & 38 & 43 & 39 \\
\hline 16 & Campinas & 10 & 1 & 11 & 8 & 1 & 9 & 36 & 39 & 36 \\
\hline 17 & Campinas & 5 & 2 & 7 & 4 & 2 & 6 & 33 & 29 & 32 \\
\hline \multirow[t]{6}{*}{ Total } & & 252 & 47 & 299 & 175 & 34 & 209 & NA & NA & NA \\
\hline & Média & 15 & 3 & 18 & 10 & 2 & 12 & 40 & 37 & 39 \\
\hline & Máximo & 22 & 8 & 26 & 14 & 5 & 16 & 55 & 45 & 51 \\
\hline & Mínimo & 5 & 1 & 7 & 4 & 1 & 6 & 33 & 29 & 32 \\
\hline & Desvio-padrão & 4 & 2 & 5 & 2 & 1 & 3 & 5 & 4 & 4 \\
\hline & Desvio-padrão/Média & $30 \%$ & $66 \%$ & $29 \%$ & $23 \%$ & $58 \%$ & $23 \%$ & $13 \%$ & $11 \%$ & $11 \%$ \\
\hline
\end{tabular}


A Tabela 2 confronta o planejamento amostral, considerando erro estatístico de $15 \%$, com as respostas obtidas para cada turma, e a variação entre o planejado e o realizado.

Percebe-se que, em termos de erro estatístico, a amostragem realizada apresentou variações em relação à que foi prevista para a maior parte das turmas analisadas, não se observando uma tendência localizada em alguma turma em especial. As variações implicaram em um erro máximo de $100 \%$ na turma 16, de Campinas, em que nenhum dos egressos foi localizado, e no erro mínimo de $10 \%$ na turma 15, de Curitiba. O erro médio calculado para todas as turmas foi de $20 \%$. Essa distorção decorreu das dificuldades de se localizar os egressos, já que parte significativa dos formados, ao ser contatada, contribuiu de maneira muito satisfatória. Tal dimensão de erro amostral não foi considerada como impedimento à pesquisa, mas sim, como um elemento importante do estudo que, futuramente, poderá ser sanado com um acompanhamento permanente ainda mais próximo dos egressos. Como conseqüência, a amostragem deixa de ser aleatória para ser nãoprobabilística, tendo sido considerados os sujeitos que atenderam à solicitação, respondendo ao questionário de atualização. O estudo ganha caráter exploratório, sendo que suas conclusões não podem ser generalizadas para a população de egressos do programa.

Tabela 2 - Turmas - Perfil da amostra (Realizado x Planejado)

\begin{tabular}{|c|c|c|c|c|c|c|c|c|c|c|c|}
\hline \multirow{2}{*}{ Turma } & \multirow{2}{*}{ Local } & \multicolumn{3}{|c|}{ Sexo masculino } & \multicolumn{3}{|c|}{ Sexo feminino } & \multicolumn{3}{|c|}{ Total } & \multirow{2}{*}{ Erro } \\
\hline & & Real. & Plan. & Var. & Real. & Plan. & Var. & Real. & Plan. & Var. & \\
\hline 1 & São Paulo & 12 & 12 & 0 & 2 & 1 & 1 & 14 & 13 & 1 & $14 \%$ \\
\hline 2 & São Paulo & 7 & 10 & (3) & 0 & 1 & (1) & 7 & 11 & (4) & $30 \%$ \\
\hline 3 & São Paulo & 7 & 12 & (5) & 1 & 1 & 0 & 8 & 13 & (5) & $25 \%$ \\
\hline 4 & São Paulo & 7 & 10 & (3) & 1 & 1 & (0) & 8 & 11 & (3) & $23 \%$ \\
\hline 5 & São Paulo & 14 & 14 & (0) & 0 & 2 & (2) & 14 & 16 & (2) & $17 \%$ \\
\hline 6 & São Paulo & 6 & 10 & (4) & 2 & 2 & (0) & 8 & 12 & (4) & $24 \%$ \\
\hline 7 & São Paulo & 11 & 11 & (0) & 2 & 4 & (2) & 13 & 15 & (2) & $18 \%$ \\
\hline 8 & São Paulo & 10 & 10 & 0 & 3 & 3 & 0 & 13 & 13 & 0 & $15 \%$ \\
\hline 9 & São Paulo & 7 & 11 & (4) & 2 & 5 & (3) & 9 & 16 & (7) & $28 \%$ \\
\hline 10 & São Paulo & 6 & 12 & (6) & 0 & 2 & (2) & 6 & 14 & (8) & $34 \%$ \\
\hline 11 & São Paulo & 7 & 9 & (2) & 2 & 3 & (1) & 9 & 12 & (3) & $22 \%$ \\
\hline 12 & São Paulo & 7 & 9 & (2) & 2 & 1 & 1 & 9 & 10 & (1) & $17 \%$ \\
\hline 13 & Curitiba & 12 & 11 & 1 & 1 & 2 & (1) & 13 & 13 & 0 & $18 \%$ \\
\hline 14 & Curitiba & 9 & 9 & 0 & 1 & 1 & - & 10 & 10 & 0 & $21 \%$ \\
\hline 15 & Curitiba & 16 & 14 & 2 & 1 & 1 & (0) & 17 & 15 & 2 & $10 \%$ \\
\hline 16 & Campinas & 0 & 8 & (8) & 0 & 1 & (1) & - & 9 & (9) & $100 \%$ \\
\hline 17 & Campinas & 1 & 4 & (3) & 1 & 2 & (1) & 2 & 6 & (4) & $55 \%$ \\
\hline Total & & 139 & 175 & (36) & 21 & 34 & (13) & 160 & 209 & (49) & $20 \%$ \\
\hline
\end{tabular}


As variáveis de interesse para a pesquisa estão descritas na Tabela 3, sendo caracterizadas. Foram estruturadas de maneira a considerar aspectos de identificação de potenciais clusters (idade, sexo, curso em que se graduou, tempo de formado), bem como variáveis ligadas ao curso (notas, freqüência e avaliação qualitativa do curso pelo aluno).

Tabela 3 - Variáveis significativas na análise

\begin{tabular}{l|l}
\hline Descrição & Caracterização \\
\hline Aluno (número seqüencial) & Qualitativa categórica nominal \\
Idade & Quantitativa discreta \\
Sexo & Qualitativa categórica nominal \\
Posição profissional no início do curso & Qualitativa categórica ordinal \\
Graduação (curso) & Qualitativa categórica nominal \\
Tempo de formado & Quantitativa discreta \\
Tempo de encerramento do curso & Quantitativa discreta \\
Empresa (mesma início e após o curso) & Qualitativa categórica nominal \\
Local do curso & Qualitativa categórica nominal \\
Avaliação nas disciplinas cursadas & Quantitativa discreta \\
Freqüência no curso & Quantitativa contínua \\
Avaliação do curso pelo aluno & Qualitativa categórica ordinal \\
\hline
\end{tabular}

Os instrumentos considerados "mais robustos" podem ser utilizados no terreno das Ciências Sociais; entretanto, em muitos casos, devido às condições de obtenção de dados, é mais indicada uma abordagem qualitativa. Dessa maneira, o tratamento estatístico sobre a amostra leva em conta:

Estatística descritiva: distribuição de freqüência, média, mínimo, máximo e desvio-padrão;

Tabela de contingência analisando a correlação entre as variáveis de interesse da análise, identificando o $p$-value de cada cruzamento de variáveis com a pretensão de aceitação do nível de significância de $5 \%$.

\section{ANÁLISE DA EVOLUÇÃO PROFISSIONAL}

A primeira questão que se apresenta, nesse aspecto, é o que significa progresso profissional propriamente dito. Pode ter conotação de evolução na carreira (por alteração de posição hierárquica), monetária (variação do salário dos profissionais), reconhecimento no mercado (tornando-se referência), etc. Do ponto de vista desta pesquisa, a evolução em termos de posição na empresa foi considerada a mais relevante e factível, dadas as dificuldades práticas que as outras alternativas apresentam. Dessa maneira, os alunos foram classificados a partir da evolução na estrutura hierárquica da entidade, sendo estruturada uma classificação levando em conta a sua evolução, a partir de uma escala Likert simplificada, com 4 pontos, dois opostos semânticos, um ponto neutro e uma alternativa para respostas em que não seja possível fazer a classificação, como no caso de uma aposentadoria, por exemplo:

Caso a posição final seja inferior à posição inicial 1

Caso a posição final seja igual à

posição inicial

Caso a posição final seja superior à

posição inicial

Caso a resposta não seja pertinente 4

A classificação acima simplifica a evolução na carreira, mas permite focar de maneira abrangente os aspectos mais significativos que correspondem à tendência da progressão profissional, ainda que a intensidade não seja captada. Para que essa classificação fosse possível, uma estrutura de evolução profissional foi construída e oferecida aos alunos, conforme descrito na Tabela 4. 
Tabela 4 - Evolução na estrutura hierárquica

\begin{tabular}{lllllll}
$\mathbf{1}$ & $\mathbf{2}$ & $\mathbf{3}$ & $\mathbf{4}$ & $\mathbf{5}$ & $\mathbf{6}$ & $\mathbf{7}$ \\
\hline Não trabalhava & Analista & Supervisor & Gerente & Diretor & Sócio & Outros \\
\hline
\end{tabular}

Algumas limitações são percebidas como evidentes e toleradas pela abordagem:

1. em vários casos, houve troca de empregador, sendo que a troca envolveu entidades tanto de maior como menor portes; $\mathrm{e}$

2. alguns alunos trocaram de ambiente profissional, deixando de ser funcionários para se tornarem sócios de organizações de porte inferior ao do emprego anterior, com conseqüências sobre salários, status e mesmo atuação profissional; do total de respondentes, atualmente, 19 são sócios de empresas de consultoria, contabilidade e auditoria e 5 classificaram-se como autônomos (15\% do total).

Por outro lado, percebe-se que existe uma combinação de faixa etária e predisposição para aposentadoria que torna a análise ainda mais complexa. Finalmente, em relação a este quesito, o salário atual dos participantes deixou de ser o grande indicador porque, embora a sua obtenção tenha sido possível, a forma de comparar se tornaria muito complexa em decorrência das várias formas de recebimento e mesmo de periodicidade.

A Tabela 5 espelha a posição da amostra em termos de perfil encontrado. Pela tabela pode ser percebido que a preponderância dos alunos teve um crescimento significativo dentro das estruturas empresariais em que se mediu a sua evolução. A classificação como 1 indica que o participante atualmente se encontra num nível profissional inferior ao que estava quando iniciou o curso. A classificação como 2 indica que ele está na mesmo nível hierárquico em que estava no início do curso e a $\mathbf{3}$ considera que houve progresso, subindo na hierarquia da entidade. Na amostra, cerca de $58 \%$ apresentaram progressos. É relevante, ainda, que a permanência do aluno na mesma empresa seja de cerca de $43 \%$ do total, com pico de $83 \%$ para a turma 10 , um dado significativo para as empresas preocupadas com a retenção dos profissionais quando sua qualificação passa a ser percebida pelo mercado.
Tabela 5 - Turmas - Perfil da amostra x Evolução profissional

\begin{tabular}{c|rrrrr|r}
\hline Turma & 1 & 2 & 3 & 4 & Total & $\begin{array}{r}\text { Mesma } \\
\text { Empresa }\end{array}$ \\
\hline 1 & 0 & 3 & 10 & 1 & 14 & $21 \%$ \\
2 & 0 & 2 & 4 & 1 & 7 & $57 \%$ \\
3 & 1 & 2 & 5 & 0 & 8 & $25 \%$ \\
4 & 0 & 5 & 3 & 0 & 8 & $38 \%$ \\
5 & 2 & 3 & 8 & 1 & 14 & $14 \%$ \\
6 & 1 & 4 & 3 & 0 & 8 & $63 \%$ \\
7 & 1 & 4 & 8 & 0 & 13 & $62 \%$ \\
8 & 0 & 4 & 9 & 0 & 13 & $31 \%$ \\
9 & 0 & 2 & 7 & 0 & 9 & $22 \%$ \\
10 & 0 & 2 & 4 & 0 & 6 & $83 \%$ \\
11 & 1 & 3 & 5 & 0 & 9 & $67 \%$ \\
12 & 0 & 6 & 2 & 1 & 9 & $56 \%$ \\
13 & 1 & 3 & 9 & 0 & 13 & $38 \%$ \\
14 & 0 & 4 & 6 & 0 & 10 & $0 \%$ \\
15 & 1 & 7 & 8 & 1 & 17 & $65 \%$ \\
16 & 0 & 0 & 0 & 0 & 0 & $\mathrm{NA}$ \\
17 & 0 & 0 & 2 & 0 & 2 & $50 \%$ \\
\hline Total & 8 & 54 & 93 & 5 & 160 & $43 \%$ \\
\hline$m$ & $5 \%$ & $34 \%$ & $58 \%$ & $3 \%$ & $100 \%$ & \\
\hline
\end{tabular}

\section{ANÁLISE DO DESEMPENHO ESCOLAR}

A análise do desempenho escolar do aluno foi efetuada pelos conceitos obtidos nas disciplinas cursadas, levando em conta os critérios definidos na Tabela 6.

Tabela 6 - Equalização de notas

\begin{tabular}{lccc} 
Conceitos & A & B & C \\
\hline Faixa de notas & $>$ de 8,5 & $6,5><8,5$ & $5><6,5$ \\
\hline
\end{tabular}

Para facilitar o tratamento estatístico, os conceitos foram transformados em notas considerando-se o mínimo para cada faixa. Assim, o conceito "A" foi transformado na nota 8,5 e assim por diante. Em algumas disciplinas, além de atribuir o conceito "A", "B" ou "C", o docente discriminou-os com "+" e "-", sendo essa atitude objeto de tratamento. 
A freqüência dos alunos às disciplinas foi apurada, bem como a média total, por aluno e por turma. Tal variável foi calculada a partir da base percentual (número de aulas em que teve presença sobre total das aulas). A Tabela 7 apresenta as principais estatísticas calculadas para nota e freqüência da amostra.

Tabela 7 - Estatísticas para Nota e Freqüência

\begin{tabular}{lcc} 
Estatística & Nota & Freqüência \\
\hline Média & 7,38 & $97,0 \%$ \\
Desvio-padrão & 0,40 & $3,0 \%$ \\
Mínimo & 6,48 & $85,8 \%$ \\
10. Quartil & 7,14 & $95,0 \%$ \\
Mediana & 7,42 & $98,1 \%$ \\
2o. Quartil & 7,42 & $99,2 \%$ \\
Máximo & 8,25 & $100,0 \%$ \\
\hline
\end{tabular}

Percebe-se a pequena variação entre os egressos. Isso se deve, primordialmente, aos critérios de aprovação do programa que exige média geral "B" e freqüência de $85 \%$ para conclusão do curso.
O mínimo encontrado para as variáveis reproduz exatamente a exigência.

Outro efeito advém da utilização de conceitos que expressam pouca discriminação entre o desempenho, por exemplo, de um aluno que obteve nota 10,0 e outro com nota 8,5. Uma sugestão aos responsáveis pelo programa seria adotar o esquema de notas de 0,0 a 10,0, com média 7,0 para aprovação. Esse esquema reproduz os níveis de rigor já exigidos e permitiria melhor discriminação do desempenho dos alunos em futuras pesquisas.

\section{PERCEPÇÃO DO IMPACTO DO CURSO SOBRE A EVOLUÇÃO PROFISSIONAL, PELO ALUNO}

Foi solicitado ao aluno que definisse sua opinião em termos de impacto que o curso possa ter tido em relação à sua carreira, levando em conta a escala Likert, a partir dos opostos semânticos, em 5 categorias, indicada na Tabela 8.

Tabela 8 - Impacto do curso sobre a carreira

\begin{tabular}{lllll}
$\mathbf{1}$ & $\mathbf{2}$ & $\mathbf{3}$ & $\mathbf{4}$ & $\mathbf{5}$ \\
\hline Nenhum impacto & Pequeno impacto & Médio impacto & Grande impacto & Muito grande \\
\hline
\end{tabular}

Tal avaliação é importante para que se possa capturar a percepção que o aluno tem e analisar sua consistência com a evolução efetivamente ocorrida e o desempenho acadêmico do egresso.

A Tabela 9 reproduz o impacto do curso percebido pelos egressos, por turma. Cerca de $66 \%$ dos egressos consideraram que o impacto foi grande ou muito grande. Apenas $10 \%$ dos egressos (15 alunos) consideraram que houve nenhum impacto ou impacto pequeno. As razões para essas avaliações serão pesquisadas e aprofundadas em estudos futuros. Ainda, 4 alunos classificaram o impacto como "Outro" e 1 aluno não soube avaliar. 
Tabela 9 - Turmas - Perfil da amostra x Opinião do aluno

\begin{tabular}{|c|c|c|c|c|c|c|}
\hline Turma & $\begin{array}{c}\text { Nenhum } \\
1\end{array}$ & $\begin{array}{c}\text { Pequeno } \\
2\end{array}$ & $\begin{array}{c}\text { Médio } \\
3\end{array}$ & $\begin{array}{c}\text { Grande } \\
4\end{array}$ & $\begin{array}{c}\text { Muito grande } \\
5\end{array}$ & Total \\
\hline 1 & 0 & 1 & 4 & 5 & 3 & 13 \\
\hline 2 & 0 & 2 & 4 & 1 & 0 & 7 \\
\hline 3 & 0 & 1 & 0 & 2 & 3 & 6 \\
\hline 4 & 0 & 2 & 4 & 2 & 0 & 8 \\
\hline 5 & 0 & 1 & 3 & 9 & 1 & 14 \\
\hline 6 & 0 & 0 & 1 & 5 & 1 & 7 \\
\hline 7 & 1 & 0 & 3 & 5 & 4 & 13 \\
\hline 8 & 2 & 2 & 3 & 6 & 0 & 13 \\
\hline 9 & 1 & 0 & 5 & 2 & 1 & 9 \\
\hline 10 & 0 & 0 & 1 & 3 & 2 & 6 \\
\hline 11 & 0 & 1 & 3 & 4 & 1 & 9 \\
\hline 12 & 0 & 0 & 4 & 5 & 0 & 9 \\
\hline 13 & 0 & 0 & 4 & 7 & 2 & 13 \\
\hline 14 & 0 & 0 & 5 & 2 & 1 & 8 \\
\hline 15 & 0 & 1 & 5 & 9 & 3 & 18 \\
\hline 16 & NA & NA & NA & NA & NA & NA \\
\hline 17 & 0 & 0 & 2 & 0 & 0 & 2 \\
\hline Total & 4 & 11 & 51 & 67 & 22 & 155 \\
\hline Média & $3 \%$ & $7 \%$ & $33 \%$ & $43 \%$ & $14 \%$ & $100 \%$ \\
\hline
\end{tabular}

Foi pesquisada a relação entre impacto percebido e ano de conclusão do curso. As informações estão demonstradas na Tabela 10. Foram aglutinados os impactos "Nenhum" e "Pequeno" e, também, "Grande" e "Muito Grande".

Tabela 10 - Opinião do aluno (\%) x Ano de Conclusão

\begin{tabular}{|c|c|c|c|c}
\hline Ano de Conclusão & $\begin{array}{c}\text { Nenhum+ } \\
\text { Pequeno }\end{array}$ & Médio & $\begin{array}{c}\text { Grande + } \\
\text { Muito Grande }\end{array}$ & $\begin{array}{c}\text { Alunos } \\
\text { Formados }\end{array}$ \\
1995 & $15,0 \%$ & $40,0 \%$ & $45,0 \%$ & 20 \\
1996 & $21,4 \%$ & $28,6 \%$ & $50,0 \%$ & 14 \\
1997 & $5,1 \%$ & $23,1 \%$ & $71,8 \%$ & 39 \\
1998 & $19,2 \%$ & $23,1 \%$ & $57,7 \%$ & 26 \\
1999 & $3,3 \%$ & $40,0 \%$ & $56,7 \%$ & 30 \\
2000 & $3,8 \%$ & $46,2 \%$ & $50,0 \%$ & 26 \\
\hline
\end{tabular}

Não foi percebida uma relação entre o impacto e o tempo de formado no curso. A avaliação de impacto atingiu seu máximo para turmas formadas em 1997, com $71,8 \%$ dos egressos desse ano avaliando-o como "Grande" e "Muito Grande". Esse foi o ano com o maior número de formados, 39 alunos. 
As informações são apresentadas no Gráfico 1 para permitir melhor visualização.

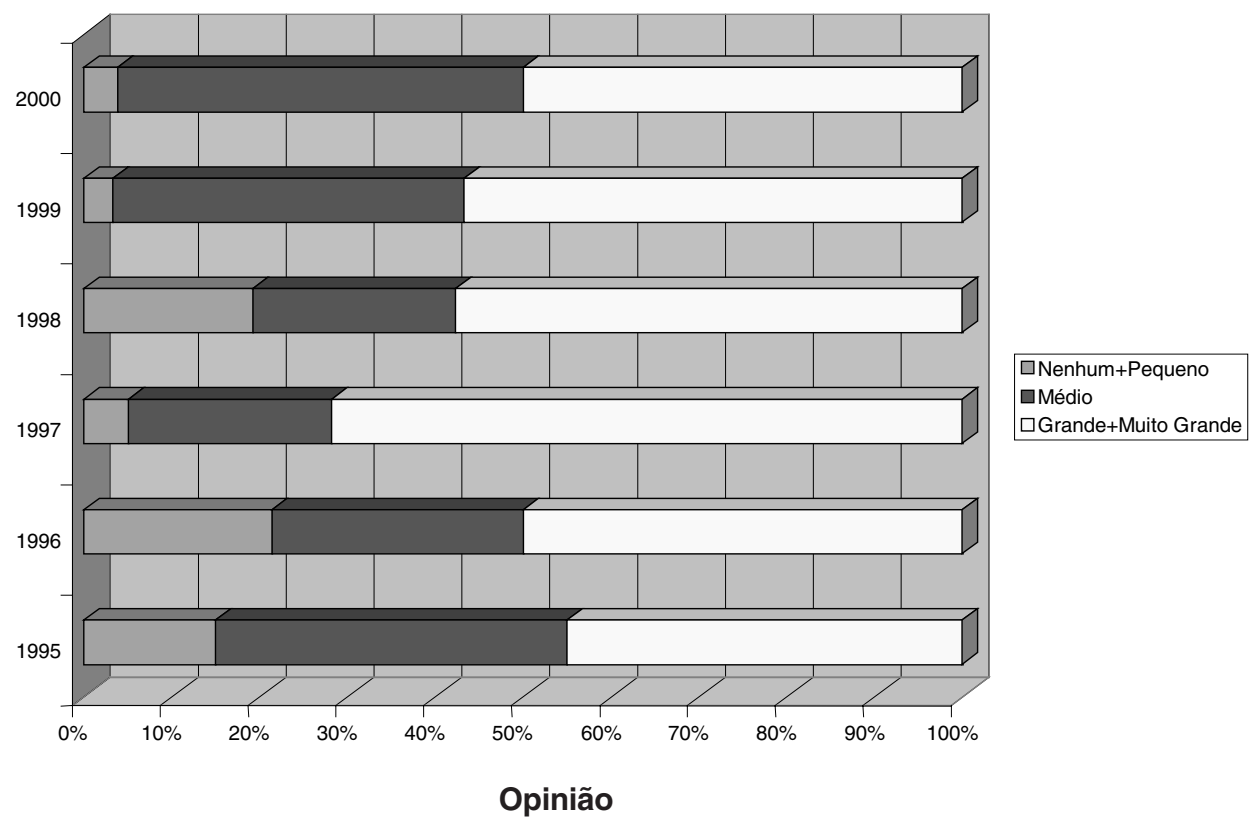

Gráfico 1 - Opinião x Ano de Conclusão

\section{RELACIONAMENTO DO DESEMPENHO ACADÊMICO, EVOLUÇÃO PROFISSIONAL E IMPACTO DO CURSO}

A Tabela 11 pretende cruzar o desempenho dos alunos em termos de desempenho nas notas, freqüência, idade atual e sua própria avaliação sobre o curso.

Tabela 11 - Evolução profissional em relação ao ingresso

\begin{tabular}{l|c|c|c|c|c|c|c} 
& Alunos & $\%$ & Notas & Freqüência & $\begin{array}{c}\text { Tempo de } \\
\text { formado }\end{array}$ & $\begin{array}{c}\text { Idade } \\
\text { atual }\end{array}$ & $\begin{array}{c}\text { Avaliação } \\
\text { Aluno }\end{array}$ \\
Posição final inferior & 10 & $6 \%$ & 7,5 & $97,1 \%$ & 18,3 & 42,3 & 3,6 \\
Posição final igual & 55 & $34 \%$ & 7,4 & $97,3 \%$ & 16,4 & 48,3 & 3,3 \\
Posição final superior & 95 & $59 \%$ & 7,4 & $96,8 \%$ & 16,3 & 40,9 & 3,6 \\
Total & 160 & $100 \%$ & 7,4 & $97 \%$ & 16,5 & 43,5 & 3,5 \\
\hline
\end{tabular}

Em termos de média final não se percebe distinção entre os três grupos que possa ser relacionada com o sucesso profissional. Da mesma forma a freqüência às aulas não serve como discriminante.

Por outro lado, os alunos que mais evoluíram em termos de posições na carreira fazem parte de uma faixa etária menor, o que pode indicar que existe um momento ideal para ingresso no curso, no qual seu impacto é maximizado.

Por fim, no que se refere à avaliação do impacto do curso sobre a carreira, a avaliação mais fa- vorável do curso é feita pelos alunos com maior progressão. Os alunos que ocupam atualmente posição inferior na carreira também fizeram uma avaliação positiva do impacto do curso, o que indica que talvez a expectativa de evolução profissional tenha sido frustrada por terem idade, em média, superior aos demais grupos e acabem não se beneficiando tanto quanto os mais jovens.

A Tabela 12 relaciona o desempenho acadêmico considerando conceitos e notas com a progressão profissional dos egressos. 
Tabela 12 - Cruzamento de desempenho em notas e evolução profissional

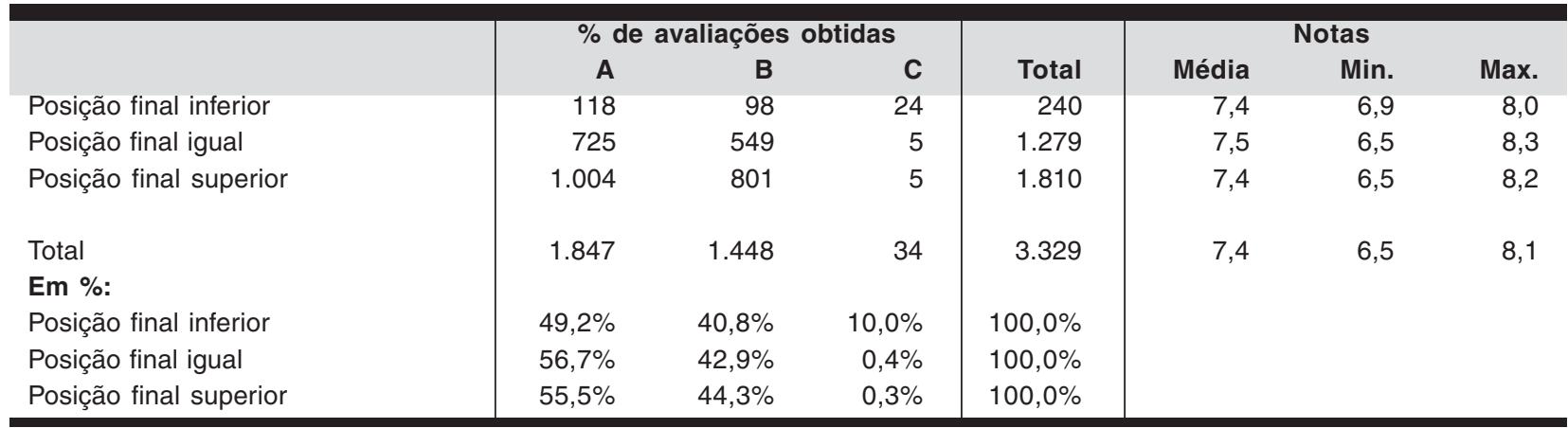

Percebe-se que os alunos que tiveram mais sucesso em termos de ascensão hierárquica tiveram número maior de "As" nas várias disciplinas que cursaram. Os alunos com involução na carreira apresentaram o maior percentual de conceitos "Cs" nas disciplinas cursadas: $10,0 \%$ do total, o que pode ser uma evidência do relacionamento entre desempenho nas disciplinas e sucesso profissional. No que se refere a notas máximas e mínimas, não se percebe nenhum fator discriminante muito acentuado. Confirma-se, assim, a necessidade de se repetir o estudo com um esquema de avaliação que permita maior discriminação entre o desempenho acadêmico dos alunos no curso.

A Tabela 13 apresenta os resultados da Análise por Tabela de Contingência. As variáveis examinadas foram: Média, Idade atual, Curso de graduação, Tempo de formado e Impacto Percebido.

Tabela 13 - Análise das variáveis relevantes ( $p$-value na segunda linha)

\begin{tabular}{|c|c|c|c|c|c|c|}
\hline & Progresso & Média & $\begin{array}{r}\text { Idade } \\
\text { atual }\end{array}$ & $\begin{array}{l}\text { Curso de } \\
\text { graduação }\end{array}$ & $\begin{array}{r}\text { Tempo de } \\
\text { formado }\end{array}$ & $\begin{array}{r}\text { Impacto } \\
\text { percebido }\end{array}$ \\
\hline $\begin{array}{l}\text { Média } \\
\text { (Pearson) }\end{array}$ & $\begin{array}{l}0,0010 \\
0,9890\end{array}$ & & & & & \\
\hline $\begin{array}{l}\text { Idade atual } \\
\text { (Pearson) }\end{array}$ & $\begin{array}{r}-0,0920 \\
0,2460\end{array}$ & $\begin{array}{r}-0,0670 \\
0,3980\end{array}$ & & & & \\
\hline $\begin{array}{l}\text { Curso graduação } \\
\text { (Pearson) }\end{array}$ & $\begin{array}{r}-0,0910 \\
0,2540\end{array}$ & $\begin{array}{r}-0,1100 \\
0,1680\end{array}$ & $\begin{array}{r}-0,0160 \\
0,8450\end{array}$ & & & \\
\hline $\begin{array}{l}\text { Tempo de formado } \\
\text { (Pearson) }\end{array}$ & $\begin{array}{r}-0,0240 \\
0,7660\end{array}$ & $\begin{array}{l}0,0120 \\
0,8760\end{array}$ & $\begin{array}{l}0,3340 \\
\mathbf{0 , 0 0 0 0}\end{array}$ & $\begin{array}{l}0,0930 \\
0,2420\end{array}$ & & \\
\hline $\begin{array}{l}\text { Impacto percebido } \\
\text { (Pearson) }\end{array}$ & $\begin{array}{l}0,0670 \\
0,4020\end{array}$ & $\begin{array}{l}0,2000 \\
\mathbf{0 , 0 0 1 0}\end{array}$ & $\begin{array}{r}-0,0080 \\
0,9240\end{array}$ & $\begin{array}{r}-0,1040 \\
0,1930\end{array}$ & $\begin{array}{l}0,1850 \\
\mathbf{0 , 0 1 9 0}\end{array}$ & \\
\hline $\begin{array}{l}\text { Seqüência de turmas } \\
\text { (Pearson) }\end{array}$ & $\begin{array}{l}0,0060 \\
0,9380\end{array}$ & $\begin{array}{r}-0,0340 \\
0,6710\end{array}$ & $\begin{array}{r}-0,0530 \\
0,5020\end{array}$ & $\begin{array}{l}0,0130 \\
0,8710\end{array}$ & $\begin{array}{r}-0,2540 \\
\mathbf{0 , 0 0 1 0}\end{array}$ & $\begin{array}{r}-0,3430 \\
\mathbf{0 , 0 0 0 0}\end{array}$ \\
\hline
\end{tabular}

As interseções que apresentam p-value (Pearson) que podem ser aceitos ao nível de $5 \%$ são:

1. Idade atual do egresso e tempo decorrido do término de sua graduação. Pode significar que o momento certo para o ingresso no programa pode ser decisivo;

2. A idade apresenta relacionamento inverso em termos de impacto nas médias obtidas, ou seja, os mais jovens tiveram avaliações mais favoráveis nas disciplinas. Por outro lado, pode-se perceber que os alunos com maior progressão profissional apresentam significativa diferenciação na faixa etária;

3. Com relação à percepção de impacto do curso por parte do aluno, o $p$-value demonstra que existe relacionamento com a média obtida $\mathrm{e}$ com o tempo de formado. Os alunos oriundos dos cursos de administração e contabilidade, neste caso, foram aqueles que tiveram o meIhor proveito do programa;

4. A turma da qual o aluno participou (foram consideradas 17) apresenta relacionamento com o tempo de formado: quanto mais antiga a 
turma, mais significativo o tempo de formado, indicado pelo sinal negativo na tabela de contingência. A turma, também, apresenta relacionamento no que se refere ao impacto percebido pelo aluno no sentido de que as turmas mais antigas valorizam mais a participação no curso.

\section{COMENTÁRIOS FINAIS}

Este trabalho apresentou um estudo exploratório do impacto de um programa MBA na evolução profissional de seus egressos. Nesse sentido, algumas das percepções e reflexões mais significativas se referem especificamente à amostra tratada, não devendo ser simplesmente generalizadas para outros ambientes, mas sim consideradas como aspectos que possam direcionar focos, pesquisas e contribuições ainda mais estruturadas em termos de pesquisa na área educacional.

No sentido de facilitar a leitura, é processado o resgate da questão de pesquisa definida neste trabalho: "quais fatores podem estar relacionados ao sucesso profissional do aluno egresso de um programa MBA?".

Foi constatado que $58 \%$ dos egressos do programa tiveram evolução profissional na carreira e cerca de $66 \%$ avaliaram positivamente o impacto causado pelo curso. Como resultado da pesquisa, alguns fatores foram percebidos como tendo impacto na evolução profissional do aluno formado, entre eles:

1. Idade do aluno ao iniciar o programa;

2. Tempo de formado;

3. Dedicação às disciplinas no sentido de obtenção das avaliações (vide Tabela 12).

De uma forma objetiva, pode-se complementar:

1. Independentemente do fato de que todo programa educacional deve ser avaliado durante o seu desenvolvimento, a análise da evolução de egressos se constitui em importante contribuição para que seja possível a análise de sucesso e correções nos casos requeridos;

2. Foco importante em termos de identificação de disciplinas deve continuamente orientar os programas educacionais; contudo, a avaliação de sua efetividade deve ser parte significativa;

3. O quesito avaliação dentro de um programa pode ser focado de várias maneiras, levando em conta simplificação ou complexidade na captura da efetividade do programa diante do que se propõe. Nesse sentido, elementos que realmente discriminem o desempenho acadêmico dos alunos devem ser foco de permanente atenção; e

4. O paralelo desta análise para outros tipos de programas educacionais se faz oportuno já que a sua efetividade é crítica para aceitação e valorização na comunidade.

\section{REFERÊNCIAS BIBLIOGRÁFICAS}

ASCHER, K. Master of business? London: Harbridge House Europe, 1984. Apud BARUCH, Yehuda; PEIPERL, Maury. The Impact of an MBA on graduate careers. Human Resource Management Journal, v. 10, n. 2, 2000.

BARUCH, Yehuda; PEIPERL, Maury. The Impact of an MBA on graduate careers. Human Resource Management Journal, v. 10, n. 2, 2000.

FOLHA de São Paulo. Guia Pós-Graduação e MBA. São Paulo, 3 Fev.2002.

FORRESTER, P. The British MBA, Cranfield: Cranfield Press, 1986. Apud BARUCH, Yehuda; PEIPERL, Maury. The Impact of an MBA on graduate careers. Human Resource Management Journal, v. 10, n. 2, 2000.

HAIR, Joseph F. et al. Multivariate data analysis. Englewood Cliffs: Prentice-Hall, 1998.
LUKER, A.; BROWERS, M. R.; POWERS, T. L. Factors influencing pursuit of the MBA degree: a student and employer perspective. Journal of Marketing Higher Education, v. 2, n. 2, 1989.

MINTZBERG, Henry; LAMPEL, Joseph. Do MBAs make better CEOs? Sorry, Dubya, it ain't necessarily so. Fortune, 19 Fev.2001.

SCHOFIELD, P. The MBA: managers only, please. Accountancy, v. 117, n. $1233,1996$.

WOOD JR., Thomaz. Cuidado: MBAs pensando. Carta Capital, 12 Dez. 2001.

WUORIO, Jeff. The Impact of the rankings: multiple perspectives. Selections, Santa Monica, v. 1, n. 2, Fall 2001. 